\title{
Изотопные (Nd-Sr) характеристики и возможные источники ультракалиевых щелочных пород Сыннырского массива (Северное Прибайкалье)
}

\author{
Саватенков В.М., Рыцк Е.Ю., Великославинский С.Д., Лебедева Ю.М. \\ Институт геологии и геохронологии докембрия РАН, Санкт-Петербург, v.m.savatenkov@ipgg.ru
}

Аннотация. Приведены результаты Rb-Sr изотопного исследования щелочных пород высококалиевой серии Сыннырского массива в неопротерозойских рифтогенных структурах Северного Прибайкалья и пуласкитов Тасского массивов, прорывающего архейские метаморфические породы курультинской толщи Алданского щита. Синтез новых и ранее полученных изотопных и геохимических данных показывает, что главным компонентом обогащенного источника высококалиевых щелочных пород этих массивов могла быть древняя континентальная кора, переработанная в результате взаимодействия с различными мантийными магмами в ходе рифтогенной деструкции Сибирского кратона и плюмовых процессов.

Ключевые слова: высококалиевые щелочные серии; $\mathrm{Nd}-\mathrm{Sr}$ изотопные характеристики; обогащенные источники; древняя континентальная кора.

\section{Isotope (Nd-Sr) features and possible sources of ultrapotassium alkaline rocks of the Synnyr massif (Northern Baikal region)}

\author{
Savatenkov V. M., Rytsk E.Yu., Velikoslavinskii S. D, Lebedeva Yu. M. \\ Institute of Geology and geochronology of the Precambrian RAS, St. Petersburg,v.m.savatenkov@ipgg.ru
}

\begin{abstract}
The paper presents results of the $\mathrm{Rb}-\mathrm{Sr}$ isotope study of alkaline rocks of the high-K series and of the Sinnyr massif intruded the Neoproterozoic rift-related rocks of the Northern Baikal region and pulaskites of the Tassky massif, intruded the Archean metamorphic rocks of the Kurulta unit of the Aldan Shield. Synthesis of new and previously obtained isotope and geochemical data shows that the main component of the enriched source of high alkali alkaline rocks could be the ancient continental crust, reworked in a result of plume processes and interaction with various mantle magmas during the rift destruction of the Siberian craton.
\end{abstract}

Key words: high potassium alkaline series; $\mathrm{Nd}-\mathrm{Sr}$ isotope characteristics; enriched sources ancient continental crust.

Сыннырский массив в Северном Прибайкалье является одним из крупнейших в мире кольце-

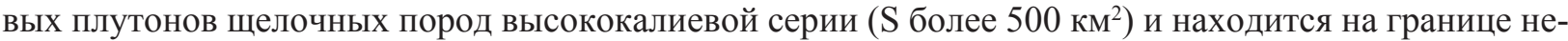
опротерозойских континентальных рифтогенных структур Олокитской зоны и Байкало-Муйского пояса (рис. 1). В строении массива выделяется центральное ядро трахитоидных пуласкитов и две зоны, сложенные дифференцированной серией щелочных пород. Во внутренней зоне преобладают щелочные, нефелиновые и кальсилитовые сиениты с телами шонкинитов и ультракалиевых псевдолейцитовых сынныритов, а в пределах внешней зоны - нефелиновые сиениты, близкие к фойяитам (Орлова и др., 1993).

Вопрос источников и происхождения высококалиевых щелочных пород, включая уникальные ультракалиевые сынныриты, открытые А.Я. Жидковым (1963), представляет сложную петрологическую проблему (Соболев и др., 1983). Большинство континентальных высококалиевых пород (Lustrino, 2016), как и щелочные породы Сыннырского массива (Рыцк и др., 2017), характеризуются коровыми Nd-изотопными характеристиками, которые указывают на значительную роль в их источнике докембрийской и в частности, палеопротерозойской континентальной коры. Вместе с тем, обогащенные компоненты источников щелочных пород могут быть связаны не только с древней континентальной корой, но и с долгоживущими резервуарами континентальной литосферной мантии. Для уточнения изотопного состава щелочных пород дифференцированной серии Сыннырского массива и комплекса даек лейцитовых фонотефритов, а также для сравнения пуласкитов Тасского массива, прорывающего архейские метаморфические породы курультинской толщи Алданского щита, выполнены дополнительные $\mathrm{Rb}-\mathrm{Sr}$ изотопные исследования. 


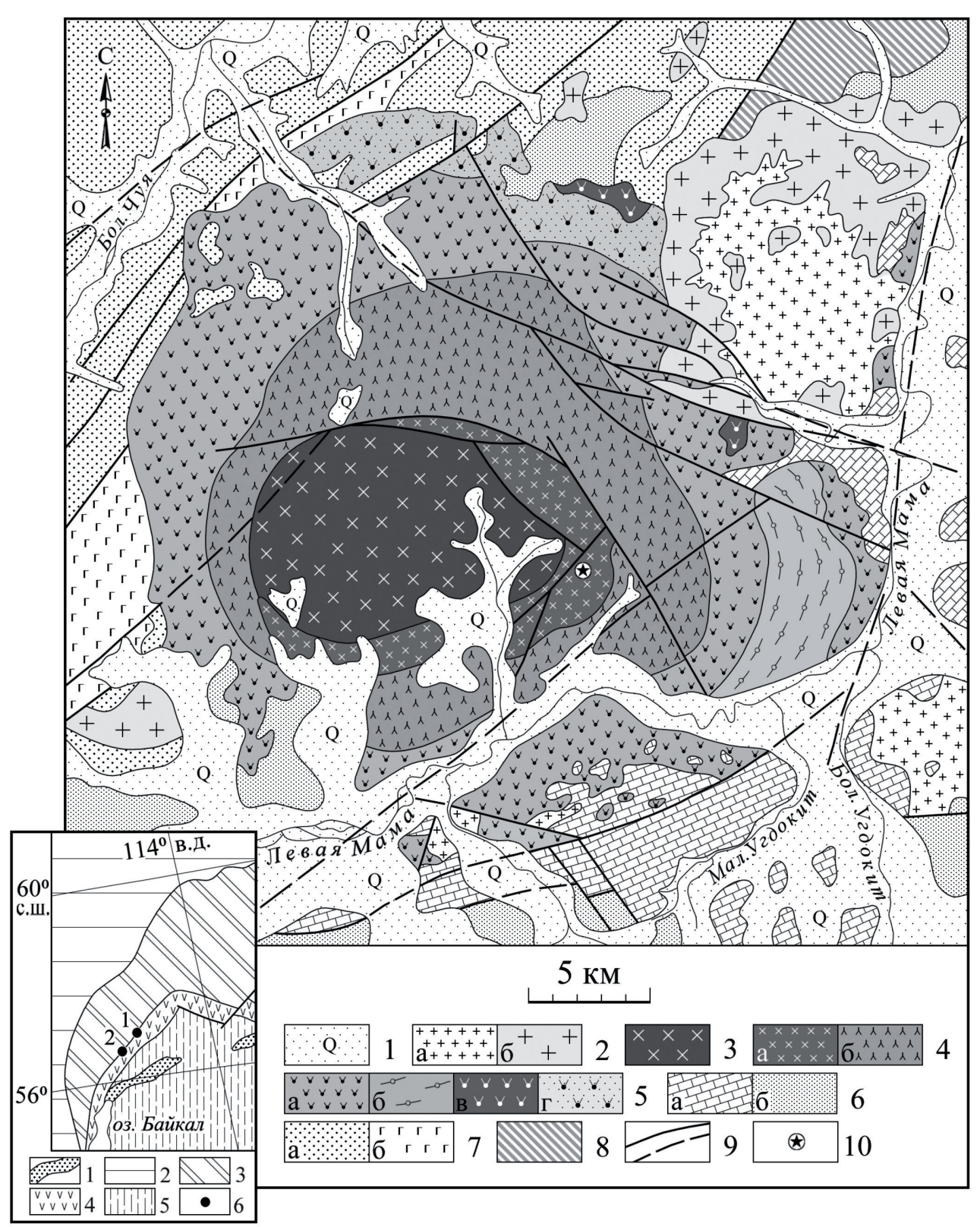

Рис. 1. Схема геологического строения Сыннырского массива щелочных пород, с изменениями по (Жидков, 1962; Орлова и др., 1993; Рыцк и др., 2017).

1 - четвертичные отложения; 2 - конкудеро-мамаканский комплекс: мелкозернистые лейкократовые граниты (а), порфировидные биотитовые и амфиболовые граниты, граносиениты и кварцевые сиениты (б); Сыннырский массив (3-5). 3 - трахитоидные пуласкиты в ядре массива; 4 - внутренняя зона массива (а-б): a - псевдолейцитовые сиениты, сынныриты, шонкиниты; б - пойкилитовые и средне-мелкозернистые нефелиновые сиениты с горизонтами псевдолейцитовых сиенитов, включающих жильные тела сынныритов; 5 - внешняя зона массива (а-г): а- среднезернистые и трахитоидные нефелиновые и нефелин содержащие сиениты; б - трахитоидные пироксеновые нефелиновые сиениты близкие к фойяитам; в - пироксен-нефелиновые сиениты малых интрузивных тел: г - эндоконтактовые амфиболовые и амфибол-пироксеновые породы сиенитового состава с обломками роговиков и эруптивные брекчии; Вмещающие толщи (6-8): 6 - анамакитская серия, известняки раннего кембрия (а) и терригенные породы (б); 7 - неопротерозойские карбонатные, метаосадочные породы (а) и метабазальты (б) Олокитской рифтогенной зоны; 8 - метаморфический комплекс раннего неопротерозоя; 9 - разрывные нарушения (установленные и предполагаемые); 10 - место отбора образцов.

Условные обозначения к врезке. 1 - четвертичные впадины; 2 - Сибирская платформа; 3 - Байкало-Патомский складчато-надвиговый пояс; 4 - Байкало-Муйский пояс; 5 - террейны Центрально-Азиатского подвижного пояса; 6 - щелочные массивы высококалиевой серии (1 - Сыннырский; 2 - Бурпалинский). 
Fig. 1. Sketch geological map of the Synnyr massif of alkaline rocks, with changes in (Zhidkov, 1962; Orlova et al., 1993; Rytsk et al., 2017).

1 - Quaternary deposits; 2 - Konkudero-Mamakanskii complex: fine-grained leucocratic granites (a), porphyry biotite and amphibole granites, granosyenites and quartz syenites (b); Synnyr massif (3-5). 3 - trachytoid pulascites in the core of the massif; 4 - internal area of the massif (a-b): $a$ - pseudo-leucite syenites, synnyrites, shonkinites; $b$ - poikilitic and medium-fine-grained nepheline syenites with horizons of pseudo-leucite syenites, including the veins of synnyrites; 5 - outer zone of the massif (a-d): a - medium-grained and trachytoid nepheline and nepheline-bearing syenites; b - trachytoid pyroxene nepheline syenites close to foyaites; (c) pyroxene-nepheline syenites of small intrusive bodies: (d) endocontact amphibole and amphibole-pyroxene rocks of syenite composition with fragments of hornfels and eruptive breccias; The host rocks (6-8): 6 - Anamakit group, early Cambrian limestones (a) and terrigenous rocks (b); 7 - Neoproterozoic carbonate, metasedimentary rocks (a) and metabasalts (b) of the Olokit rift zone; 8 - early Neoproterozoic metamorphic complex; 9 - faults (established and assumed); 10 - the place of sampling.

Symbols to the inset. 1 - Quaternary depressions; 2 - Siberian platform; 3 - The Baikal-Patom fold-thrust belt; 4 - Baikal-Muya belt; 5 - terrains of the Central Asian mobile belt; 6 - alkaline massifs of ultrapotassium series (1 - Synnyr; 2 - Burpala).

На диаграмме в координатах ${ }^{87} \mathrm{Rb} /{ }^{86} \mathrm{Sr}-{ }^{87} \mathrm{Sr} /{ }^{86} \mathrm{Sr}$ фигуративные точки изотопных составов трёх образцов сынныритов и двух образцов шонкинитов образуют эрохронную зависимость $(\mathrm{CKBO}=6.2)$ угол наклона которой отвечает возрасту $291 \pm 9$ млн. лет и первичному отношению ${ }^{87} \mathrm{Sr} /{ }^{86} \mathrm{Sr}-0.707768 \pm 0.000026$. При этом один образец сынныритов и один образец шонкинитов существенно отклоняются от этой зависимости, что скорее всего обусловлено частичным нарушением Rb-Sr изотопной системы в результате неравномерно проявленных наложенных процессов фенитизации и низкотемпературных вторичных изменений пород и (или) может свидетельствовать об исходной гетерогенности источников этих щелочных пород. Таким образом, полученное и опубликованные Rb-Sr значения «возраста» для щелочных пород массива не следует рассматривать в качестве геохронологических оценок их возраста.

Установленные изотопные параметры $\varepsilon_{\mathrm{Nd}}(\mathrm{t})$ и $\varepsilon_{\mathrm{Sr}}(\mathrm{t})$ изученных щелочных пород Сыннырского массива предполагают участие в их образовании обогащённого источника, подобного ЕМІІ (рис. 2 a), в то время как Nd-Sr характеристики пуласкитов Тасского массива указывают на обогащенный источник типа ЕMI раннего архея. При этом, по своим первичным изотопным характеристикам $\mathrm{Nd}$ породы Сыннырского массива весьма однородны $\left(\varepsilon_{\mathrm{Nd}}(\mathrm{T})\right.$ варьирует в интервале -10/-11) и сходны по этому параметру с щелочными породами Бурпалинского и Акитского массивов Северного Прибайкалья, изученных Н.В. Владыкиным (2005).

Учитывая, что в пределах Олокитской зоны континентального рифтогенеза, помимо Сыннырского щелочного массива, находится более древний (720-730 млн. лет) Довыренский расслоенный плутон с аномальными «обогащенными» изотопными параметрами долгоживущего сублитосферного мантийного источника (Амелин и др.,1996; Арискин и др., 2015), на диаграммах (см. рис. 2 a, б) также показано поле изотопных составов ультраосновных и основных пород этого плутона. Как видно, поле составов пород расслоенного плутона находится на продолжении возможного тренда для части щелочных пород, хотя низкие отношения $\mathrm{Nb} / \mathrm{Th}$ обогащенного источника более характерны для палеопротерозойской континентальной коры, к полю которой тяготеют и точки Sr-Nd изотопных составов лампроитов Алданского щита (Davies et al., 2006). Дайки лейцитовых фонотефритов, прорывающих сынныриты внутренней зоны Сыннырского массива на рубеже нижнего - среднего триаса (240-250 млн. лет, неопубликованные данные авторов), характеризуются значительно более мантийным Nd-Sr изотопным составом (см. рис. 2 a), близким к составу карбонатитовых комплексов Кольского полуострова (Kramm, Kogarko,1994; Balaganskaya et al., 2007) и Байкало-Муйского пояса (Дорошкевич и др., 2011). При этом, в координатах Nb/Th- $\varepsilon_{\mathrm{Nd}}(\mathrm{t})$ (рис. 2 б), точки составов фонотефритов и сиенитов-сынныритов образуют тренд от поля составов ДМ к полю составов протерозойской континентальной коры. Таким образом, можно заключить, что согласно имеющимся изотопным данным, главным компонентом обогащенного источника высококалиевых щелочных пород Сыннырского массива могла быть древняя континентальная кора, переработанная 
a

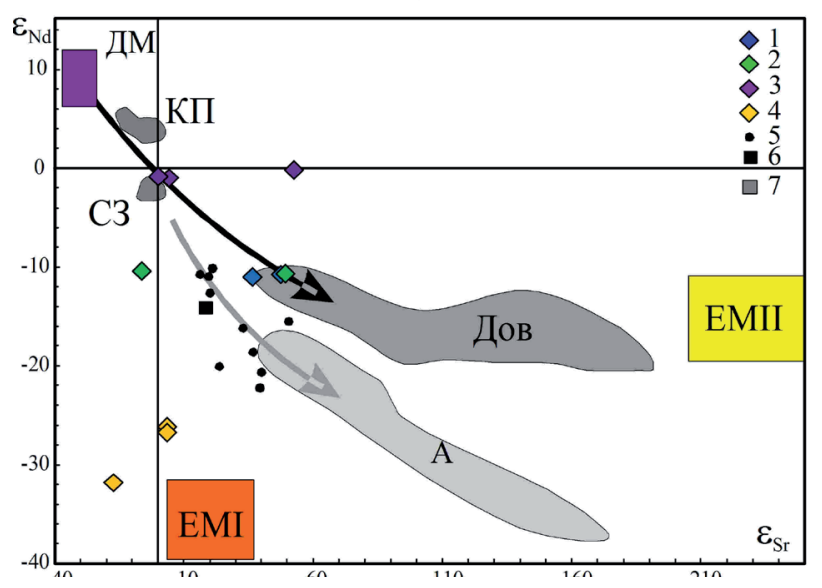

б

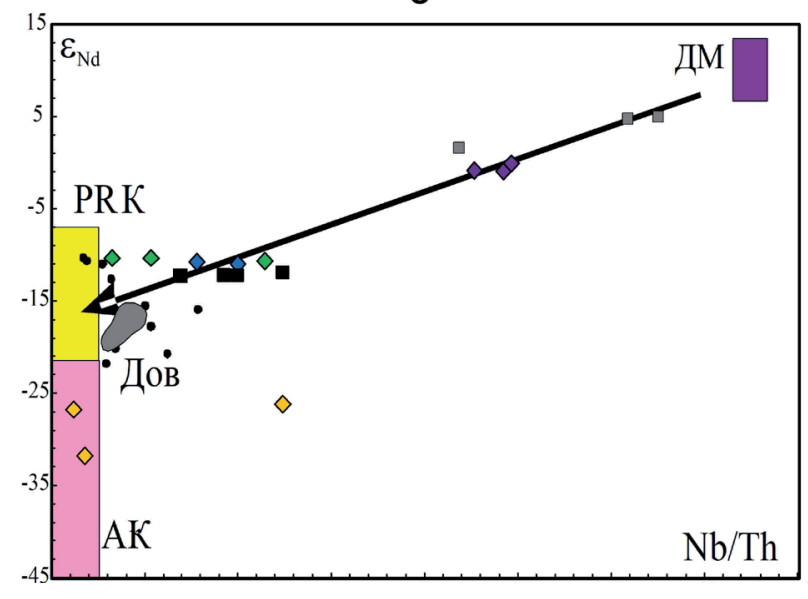

Рис. 2. Диаграммы в координатах $\varepsilon_{\mathrm{Sr}}(\mathrm{t})-\varepsilon_{\mathrm{Nd}}(\mathrm{t})(\mathrm{a})$ и $\mathrm{Nb} / \mathrm{Th}-\varepsilon_{\mathrm{Nd}}(\mathrm{t})($ б).

Сыннырский массив (1-3): 1 - сынныриты, 2 - сиениты, шонкиниты, 3 - фонотефриты, 4 - пуласкиты Тасского массива, 5 -лампроиты Алданского щита (Davies et al., 2006), 6 - лампроиты Норильского региона (Ivanov et al., 2018), 7 - высокотитанистые базальты иньяптукской свиты Олокитской зоны (Арискин и др., 2015).

Поля составов: Дов - пород Довыренского массива (Amelin et al., 1996; Арискин и др., 2015); А - архейской коры Алданского щита согласно (Neymark et al., 1993); КП -карбонатитовых комплексов Кольского полуострова (Kramm, Kogarko, 1994; Balaganskaya et al., 2006); С3 - карбонатитов Северного Забайкалья (Дорошкевич и др., 2011). ArK - пород архейской континентальной коры; PRK -протерозойской континентальной коры. ДМ - деплетированная мантия, EMI и ЕMII - обогащённые мантийные источники. Значения отношений $\mathrm{Nb} / \mathrm{Th}$ для континентальной коры по (Condie, 1993), деплетированной мантии - по (Salters, Stracke, 2004).

Fig. 2. The diagrams $\varepsilon_{\mathrm{Sr}}(\mathrm{t})-\varepsilon_{\mathrm{Nd}}(\mathrm{t})$ (a) and $\mathrm{Nb} / \mathrm{Th}-\varepsilon_{\mathrm{Nd}}(\mathrm{t})$ (б).

The Synnyr massif (1-3): 1 - synnyrites, 2 - syenites, shonkinites, 3 - phonothephrites, 4 - pulaskites of the Tasskii massif, 5 - lamproites of the Aldan Shield (Davies et al., 2006), 6 - lamproites of the Norilsk region (Ivanov et al., 2018), 7 - the high-Ti basalts of the Inyaptuk suite of the Olokit zone (Ariskin et al., 2015).

Fields of compositions: Dov - rocks of the Dovyrenskii massif (Amelin et al., 1996; Ariskin et al., 2015); A - the Archean crust of the Aldan Shield after (Neymark et al., 1993); KP - carbonatite complexes of the Kola Peninsula (Kramm, Kogarko, 1994; Balaganskaya et al., 2006); SZ - carbonatites of Northern Transbaikalia (Doroshkevich et al., 2011). ArK - rocks of the Archean continental crust; PRK - Proterozoic continental crust.

DM - depleted mantle, EMI and EMII - enriched mantle sources. Values of $\mathrm{Nb} / \mathrm{Th}$ ratios for the continental crust (Condie, 1993), depleted mantle - after (Salters, Stracke, 2004).

в результате взаимодействия с различными мантийными магмами в ходе рифтогенной деструкции Сибирского кратона и плюмовых процессов.

Работа выполнена в рамках темы НИР №0153-2019-0001, №0153-2019-0005, при поддержке РФФИ (проект №18-05-00724) и Фонда развития отечественной геологии.

\section{Литература}

1. Арискин А.А., Данюшевский Л.В., Конников Э.Г., Маас Р., Костицын Ю.А., Мак-Нил Э., Меффре С., Николаев Г.С., Кислов Е.В. Довыренский интрузивный комплекс (Северное Прибайкалье, Россия): изотопно-геохимические маркеры контаминации исходных магм и экстремальной обогащенности источника // Геология и геофизика. 2015. Т. 56. № 3. С. 528-556.

2. Владыкин Н.В. Геохимия изотопов $\mathrm{Sr}$ и $\mathrm{Nd}$ щелочных и карбонатитовых комплексов Сибири и Монголии и некоторые геодинамические следствия // Проблемы источников глубинного магматизма и плюмы. Иркутск. 2005. С. 13-29.

3. Дорошкевич А.Г., Рипп Г.С., Владыкин Н.В., Саватенков В.М. Источники карбонатитового магматизма Северного Забайкалья в позднем рифее: геохимические и изотопно-геохимические данные // Геохимия. 2011. № 12. С. 1271-1283. 
4. Жидков А.Я. Уникальное месторождение псевдолейцитовых ультракалиевых сиенитов // Докл. АН СССР. 1963. Т. 152. № 12. С. 414-417.

5. Орлова М.П., Жидков А.Я., Орлов Д.М., Зотова И.Ф. Внутренняя структура и формирование Сыннырского щелочного массива // Геохимия.1993. № 8. С.1161-1182.

6. Соболев В.С., Костюк В.П., Панина Л.И. и др. О проблеме сынныритов // Сб. Магматизм и метаморфизм зоны БАМ и их роль в формировании полезных ископаемых. 1983. С. 102-110.

7. Рыцк Е.Ю., Великославинский С.Д., Смыслов С.А., Котов А.Б., Глебовицкий В.А., Богомолов Е.С., Толмачева Е.В., Ковач В.П. Геохимические особенности и источники позднепалеозойских высококалиевых и ультракалиевых сиенитов Сыннырского и Тасского массивов (Восточная Сибирь). ДАН. 2017. Т. 476. № 1. С. 93-97.

8. Amelin Yu.V., Neymark L.A., Ritsk E.Yu., Nemchin A.A. Enriched Nd-Sr-Pb isotopic signatures in the Dovyren layered intrusion (eastern Siberia, Russia): evidence for source contamination by ancient upper-crustal material // Chemical Geology. 1996. V. 129. P. 39-69.

9. Balaganskaya E.G., Downes H., Demaiffe D. REE and Sr-Nd isotope compositions of clinopyroxenites, phoscorite sand carbonatites of the Seblyavr Massif, Kola Peninsula, Russia // Mineralogia Polonica. 2007. V. 38 . N. 1.

10. Condie K.C. Chemical composition and evolution of the upper continental crust: contrasting results from surface samples and shales // Chemical Geology. 1993. V. 104. P. 1-37.

11. Davies G.R., Stolz A.J., Mahotkin I.L., Nowell G.M., Pearson D.G. Trace Element and Sr-Pb-Nd-Hf Isotope Evidence for Ancient, Fluid-Dominated Enrichment of the Source of Aldan Shield Lamproites // Journal of Petrology. V. 47. Is. 6. 1 June 2006. P. 1119-1146.

12. Ivanov A.V., Demonterova E.I., Savatenkov V.M., Perepelov A.B., Ryabov V.V., Shevko A.Y. Late Triassic (Carnian) lamproites from Noril'sk, polar Siberia: Evidence formelting of the recycled Archean crust and the question of lamproitesourcefor some placer diamond deposits of the Siberian Craton // Lithos. 296-299 (2018) 67-78.

13. Neymark L.A., Kovach V.P., Nemchin A.A., Morozova I.M., Smelov A.P. et al. Late Archaean intrusive complexes in the Olekma granite-greenstone terrain (eastern Siberia): geochemical and isotopic study // Precambrian Research. V. 62. Is. 4. July 1993. P. 453-472.

14. Kramm U., Kogarko L.N. Nd and Sr isotope signatures of the Khibina and Lovozero agpaitic centres, Kola Alkaline province, Russia // Lithos. V. 32. Is. 3-4. July 1994. P. 225-242.

15. Lustrino, M., Agostini S., Chalal Y., Fedele L., Stagno V., Colombi F., Bouguerra A. Exotic lamproites or normal ultrapotassic rocks? The Late Miocene volcanic rocks from Kef Hahouner, NE Algeria, in the frame of the circum-Mediterranean lamproites // Journal of Volcanology and Geothermal Research. 2016. V. 327. P. $539-553$.

16. Salters V.J.M. and Stracke A. (2004). Composition of the depleted mantle. Geochemistry Geophysics Geosystems 5: doi: 10.1029/2003GC000597. issn: 1525-2027. 